\title{
Omics in Plant Disease Resistance
}

\author{
Edited by: Vijai Bhadauria \\ University of Saskatchewan, Canada
}

Published: February 2016. Pages: iv +144

ISBN: Book: 978-1-910190-35-7. Ebook: 978-1-910190-36-4 £159, \$319

Published by: Caister Academic Press www.caister.com

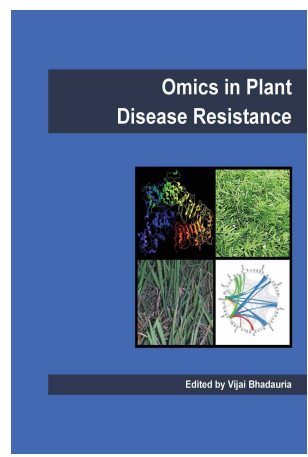

Genomics and post-genomics technologies, including genomics, transcriptomics, proteomics, metabolomics, next-generation sequencing-based genotyping and mass spectrometry, are becoming increasingly important in agricultural research and in particular for the genetic improvement of crops for disease resistance.

Distinguished scientists from around the world, under the expert guidance of the editor Vijai Bhadauria, overview and critically analyse the omics technologies currently being used in agricultural research. The authors review the practical applications and implications of these technologies in the genetic improvement of crops for resistance against various viral, bacterial and fungal diseases of economic significance. Topics include: resistance to fungal diseases in lentil, proteomic studies in rice, metabolomics of disease resistance in crops, omics approachs in Brassica, resistance to planthopper-borne viruses, resistance to root-knot nematodes, complex oomycete plant interactions, omics of pathogen resistant plants, rice-Magnaporthe interaction, role of nitric oxide, overview of proteomics tools, and pathogen resistance in legumes. In each case the authors comprehensively describe the most relevant technology, the latest applications and the most recent scientific research.

This volume is essential reading for everyone involved in plant disease resistance and crop improvement and is also highly recommended for all plant scientists.

1. OMICS in Plant Disease Resistance (Vijai Bhadauria)

2. Wild Help for Enhancing Genetic Resistance in Lentil Against Fungal Diseases (Vijai Bhadauria, Melissa M.L. Wong,

Kirstin E. Bett and Sabine Banniza)

3. Current Status of Proteomic Studies on Defense Responses in Rice (Xifeng Chen, Vijai Bhadauria and Bojun Ma)

4. Metabolomics of Disease Resistance in Crops (Vicent Arbona and Aurelio Gómez-Cadenas)

5. Omics Approach to Identify Factors Involved in Brassica Disease Resistance (Marta Francisco, Pilar Soengas, Pablo

Velasco, Vijai Bhadauria, Maria E. Cartea and Victor M. Rodríguez)

6. Rice Responses and Resistance to Planthopper-Borne Viruses at Transcriptomic and Proteomic Levels (Feng Cui, Wan Zhao, Lan Luo and Le Kang)

7. The Power of Omics to Identify Plant Susceptibility Factors and to Study Resistance to Root-knot Nematodes (Javier Cabrera, Marta Barcala, Carmen Fenoll and Carolina Escobar)

8. RNAseq and Proteomics for Analysing Complex Oomycete Plant Interactions (Dharani D. Burra, Ramesh R. Vetukuri,

Svante Resjö, Laura J. Grenville-Briggs and Erik Andreasson)

9. Omics Approaches for the Engineering of Pathogen Resistant Plants (Diego F. Gomez-Casati, María A. Pagani, María

V. Busi and Vijai Bhadauria)

10. Oscillating Transcriptome during Rice-Magnaporthe Interaction (T.R. Sharma, Alok Das, Shallu Thakur, B.N. Devanna, Pankaj Kumar Singh, Priyanka Jain, Joshitha Vijayan and Shrawan Kumar)

11. Transcriptomic Analyses on the Role of Nitric Oxide in Plant Disease Resistance (Capilla Mata-Pérez, Juan C.

Begara-Morales, Francisco Luque, María N. Padilla, Jaime Jiménez-Ruiz, Beatriz Sánchez-Calvo, Jesús Fierro-Risco and Juan B. Barroso)

12. An Overview of Proteomics Tools for Understanding Plant Defense Against Pathogens (Carolina Grandellis, Cecilia V. Vranych, Ainelén Piazza, Betiana S. Garavaglia, Natalia Gottig and Jorgelina Ottado)

13. Linking Biomarker and Comparative Omics to Pathogens in Legumes (Marwan Diapari)

\section{Order from:}

Caister Academic Press https://www.caister.com/order 


\section{CURRENT BOOKS OF INTEREST}

Porcine Viruses: From Pathogenesis to Strategies for Control

Edited by: Hovakim Zakaryan (Published: 2019)

Lactobacillus Genomics and Metabolic Engineering

Edited by: Sandra M. Ruzal (Published: 2019)

Cyanobacteria: Signaling and Regulation Systems

Author: Dmitry A. Los (Published: 2018)

Viruses of Microorganisms

Edited by: Paul Hyman and Stephen T. Abedon (Published: 2018)

Protozoan Parasitism: From Omics to Prevention and Control

Edited by: Luis Miguel de Pablos Torró and Jacob-Lorenzo Morales (Published: 2018)

Genes, Genetics and Transgenics for Virus Resistance in Plants

Edited by: Basavaprabhu L. Patil (Published: 2018)

DNA Tumour Viruses: Virology, Pathogenesis and Vaccines

Edited by: Sally Roberts (Published: 2018)

Pathogenic Escherichia coli: Evolution, Omics, Detection and Control

Edited by: Pina M. Fratamico, Yanhong Liu and Christopher H. Sommers (Published: 2018)

Postgraduate Handbook: A Comprehensive Guide for PhD and Master's Students and their Supervisors

Author: Aceme Nyika (Published: 2018)

Enteroviruses: Omics, Molecular Biology, and Control

Edited by: William T. Jackson and Carolyn B. Coyne (Published: 2018)

"frontiers in the study of the 12 species of the genus" (ProtoView); "the current most important enterovirus research"

(Biotechnol. Agron. Soc. Environ.)

Molecular Biology of Kinetoplastid Parasites

Edited by: Hemanta K. Majumder (Published: 2018)

Bacterial Evasion of the Host Immune System

Edited by: Pedro Escoll (Published: 2017)

"The figures are expertly drawn" (SIMB News)

Illustrated Dictionary of Parasitology in the Post-Genomic Era

Author: Hany M. Elsheikha and Edward L. Jarroll (Published: 2017)

"a guide for students, academic staff, medical and veterinarian professionals" (ProtoView); "an extensive and comprehensive glossary of contemporary concepts, terminologies, and vocabulary in modern parasitology" (Doodys); "a pure pleasure to explore and discover" (Epidemiol. Infect.); "highly recommended" (Biotechnol. Agron. Soc. Environ.)

Next-generation Sequencing and Bioinformatics for Plant Science

Edited by: Vijai Bhadauria (Published: 2017)

The CRISPR/Cas System: Emerging Technology and Application

Edited by: Muhammad Jamal (Published: 2017)

"reviews recent advances" (ProtoView)

Brewing Microbiology: Current Research, Omics and Microbial Ecology

Edited by: Nicholas A. Bokulich and Charles W. Bamforth (Published: 2017)

"a valuable information source ... an authoritative overview" (IMA Fungus); "a must read book" (SIMB News)

Metagenomics: Current Advances and Emerging Concepts

Edited by: Diana Marco (Published: 2017)

"presents those new to the field with important aspects of metagenomics" (Eur. J. Soil Sci.)

Bacillus: Cellular and Molecular Biology (Third edition)

Edited by: Peter L. Graumann (Published: 2017)

"a one-stop shop for a huge range of Bacillus-focused molecular biology" (Microbiology Today) 